\title{
Assessment of Maternal Mortality Ratio in Pre and Post National Rural Health Mission Period in India
}

\author{
Gulnawaz Usmani ${ }^{1 *}$ and Nighat Ahmad ${ }^{2}$ \\ ${ }^{1}$ Department of Economics, Aligarh Muslim University, India \\ ${ }^{2}$ Chair Person, Department of Economics, Aligarh Muslim University, India
}

Submission: September 15, 2017; Published: October 26, 2017

*Corresponding author: Gulnawaz Usmani, Research Scholar, Department of Economics, Aligarh Muslim University, Aligarh, India, 202002, Email: nawaz1717@gmail.com

\begin{abstract}
Maternal Health plays a vital role in the development of a country. Every country aimed to reduce MMR to the lower extent. In India National Rural Health Mission (NRHM) aimed to reduce maternal mortality ratio (MMR) to less than 100 per lakh live births. NRHM implemented in 2005 since then the program has been trying to come over the huge burden of MMR. This paper uses secondary data from Sample Registration System. The data is available from 1997-1998 to 2011-13. Hence, comparison was made between the pre and post NRHM period. The overall decline in MMR in pre NRHM period was -36.1 percent against -34.2 percent in post NRHM Period. Although, the difference is not significant. The state with highest MMR and lowest MMR has changed but the disparity between the states has remained almost constant. At the conclusion, the pace of MMR decline has not accelerate after NRHM implantation and disparity ratio has not reduced indicating that there is a dire need of some more effective healthcare programmes especially for the pregnant women.
\end{abstract}

Keywords: Maternal mortality ratio; Disparity in maternal mortality ratio; National rural health mission; India

\section{Introduction}

India is the second most populated country after the China in the world. India constitutes 36 States/union territories with huge cultural, economic, geography, infrastructure, and health standard diversity. Although, the birth and death registration is obligatory but still there are a number of cases of underreporting of vital registration to the extent of almost 30 percent. Reason may be poor access to healthcare centres, lack of awareness among poor and uneducated people of rural and some semi urban areas. Vital statistics shows that the MMR has the highest inter states disparity in India as compared to other vital indicators. Child bearing is the most hazardous experience among all experiences that a new mother engage in while she bringing her baby to this world. This stage is often associated with many complications that may cause disability, morbidity or even mortality Ayele et al. [1]. Sample Registration System (SRS) of India provide the most reliable data on maternal and child mortality. SRS is the largest and more reliable demographic sample survey in India [2]. The sample system though not included the MMR in the early statistical reports but it published the maternal mortality data periodically through special bulletins on maternal mortality ratio. In India reliable MMR data is available from the year 1997 by office of the Registrar General of India (Sample Registration System). The latest report on maternal mortality ratio is for the period of 2011-2013 [3].
Almost every country of the world has declared and set the target to reduce Maternal Mortality Ratio (MMR). India have also target MMR and setup a goal to reduce MMR to less than 100 per lakh live births by the year 2015 (UNDP, India). Today, India has 167MMR per lakh live births (SRS, 2013). National Rural Health Mission (NRHM) has aimed to reduce MMR. After the completion of 11th Five Year Plan and failure to achieve the target Government of India still trying to reduce the maternal mortality rate by introducing some new schemes and policy under the head of National Health Mission. This analysis begins with the thought that whether the National Rural health Mission helps in achieving the target of reducing maternal Mortality Rate to 109 per lakh live births by the year 2015. Analysis has been done by using Sample Registration System (SRS) data. Data on MMR is available only for the period of 1997 to 2013. In this study, a comparison is made between 8 states. These 8 states comprise 4 from northern part of the country and 4 from the southern part. We covered the period of 7 years data from 1997 98 to 2011-13. We divide it into two parts one part is pre NRHM and the other is post NRHM. We have calculated the percentage change per year in MMR and percentage change in both the period (per and post NRHM) for each state under consideration. The change in MMR per year has been calculated by dividing the difference of final value and initial value by total number of 
years and the percentage change during the pre and post NRHM period is calculated by dividing the difference of lowest and highest value by lowest value and then multiplying it by 100 . Table 1: Maternal mortality ratio in India.

\begin{tabular}{|c|c|c|c|c|c|c|c|}
\hline States & 1997-98 & 1999-01 & 2001-03 & 2004-06 & 2007-09 & 2010-12 & 2011-13 \\
\hline $\mathrm{AP}$ & 197 & 220 & 195 & 154 & 134 & 110 & 92 \\
\hline ASM & 568 & 398 & 490 & 480 & 390 & 328 & 300 \\
\hline $\mathrm{BR}$ & 531 & 400 & 371 & 312 & 261 & 219 & 208 \\
\hline GUJ & NA & 202 & 172 & 160 & 148 & 122 & 112 \\
\hline HAR & 136 & 176 & 162 & 186 & 253 & 146 & 127 \\
\hline KAR & 245 & 266 & 228 & 213 & 178 & 144 & 133 \\
\hline KER & 150 & 149 & 110 & 95 & 81 & 66 & 61 \\
\hline MP & 441 & 407 & 379 & 335 & 269 & 230 & 221 \\
\hline MAH & 166 & 169 & 149 & 130 & 104 & 87 & 68 \\
\hline ORS & 346 & 424 & 358 & 303 & 258 & 235 & 222 \\
\hline PUJ & 280 & 177 & 178 & 192 & 172 & 155 & 141 \\
\hline RAJ & 508 & 501 & 445 & 388 & 318 & 255 & 244 \\
\hline $\mathrm{TN}$ & 131 & 167 & 134 & 111 & 97 & 90 & 79 \\
\hline UP & 606 & 539 & 517 & 440 & 359 & 292 & 285 \\
\hline WB & 303 & 218 & 194 & 141 & 145 & 117 & 113 \\
\hline INDIA & 398 & 327 & 301 & 254 & 212 & 178 & 167 \\
\hline
\end{tabular}

Source: Sample registration system, Office of registrar general, New Delhi, India, NA: Not Available

Table 2: Decline in MMR in northern and southern states in pre and post NRHM period in India.

\begin{tabular}{|c|c|c|c|c|c|c|c|c|c|}
\hline \multirow{2}{*}{ Year } & \multicolumn{4}{|c|}{ Northern States } & \multicolumn{4}{|c|}{ Southern States } & \multirow{2}{*}{ India } \\
\hline & BR & UP & HAR & RAJ & KER & TN & AP & KAR & \\
\hline 1997 & 531 & 606 & 136 & 508 & 150 & 131 & 197 & 245 & 398 \\
\hline 2004 & 312 & 440 & 186 & 388 & 95 & 111 & 154 & 213 & 254 \\
\hline$\%$ Decline/year & -31.2 & -23.7 & 7.14 & -16.7 & -7.85 & -2.8 & -6.14 & -4.5 & -20.6 \\
\hline$\%$ Change & -41.2 & -27.3 & 36.7 & -23.6 & -36.6 & -15.2 & -21.8 & -13 & -36.1 \\
\hline 2005 & 312 & 440 & 186 & 388 & 95 & 111 & 154 & 213 & 254 \\
\hline 2013 & 208 & 285 & 127 & 244 & 61 & 79 & 92 & 133 & 167 \\
\hline \%Decline/year & -14.8 & -22.1 & -8.4 & -20.05 & -4.8 & -4.5 & -8.8 & -11.4 & -12.4 \\
\hline$\%$ Change & -33.3 & -35.2 & -31.7 & -37.1 & -35.7 & -28.8 & -40.2 & -37.5 & -34.2 \\
\hline
\end{tabular}

Range of MMR (Maternal Mortality Rate) during 1997-2004 and 2005-2013 is shown in Table 1. In 1997-98 MMR range was 398; while recently in 2011-13 it are 167 per lakh live births in India. State wise scenario of MMR also explaining the same pattern of MMR. Before the introduction of NRHM In 1997-98 the MMR range was 131(Tamil Nadu)-606 (Uttar Pradesh) while after the launch of NRHM the range of MMR is 61 (Tamil Nadu) to 285 (Uttar Pradesh). However, at country level it shows a higher reduction of MMR in the pre NRHM period (-36.1 percent) as compared to the post NRHM period ( -34.2 percent). Per year declining rate is also somewhat less in the post NRHM period than pre NRHM period. From 1997-2004 per year declining rate
We consider 8 states namely Bihar, Uttar Pradesh, Haryana and Rajasthan (northern states) and Karnataka, Kerala, Tamil Nadu and Andhra Pradesh (southern states) (Table 1). 
NRHM period is recorded in the states of Andhra Pradesh (-40.2 percent) followed by Karnataka (-37.5), Kerala (-35.7). From the northern states Rajasthan has recorded the highest percentage change in MMR. Rajasthan has shown a reduction of -37.1 percent in post NRHM period followed by the states of Uttar Pradesh (-35.2), Bihar (-33.3) and Haryana (-31.7).

Table 2 shows that the pace of MMR reduction is found to be good enough in both pre and post NRHM period. The reproductive and child health program has started in the year 1997 which we take as the base year of our analysis. The percentage change per year in MMR and percentage change in eight states in pre and post NRHM period has been shown in the Table 2. We can also say from the above table that the decline in points per year is higher in northern states as compared to southern states. Haryana is showing the positive growth in MMR in pre NRHM period i.e. 1997-2004. Haryana has recorded 7.14 percent growth in MMR per year while after the launch of NRHM state record a reduction as found about -8.4 percent in MMR per year. If we look state wise then only three states are there where the MMR is below 100. Kerala, Tamil Nadu and Andhra Pradesh have 61, 79 and 92 MMR per lakh live births in 201113. Yet, northern part of the country is showing more pace in MMR reduction, southern part get more achievement in terms of lower MMR. With this pace of reduction in MMR, India may attain her target of reducing MMR to 109 albeit, two-three years later by schedule year i.e. by 2017-18 Hanimi et al. [4]. This pace of decline may be faster by improving existing programs and by implementing more maternal healthcare programs and cash incentive schemes to the poor.

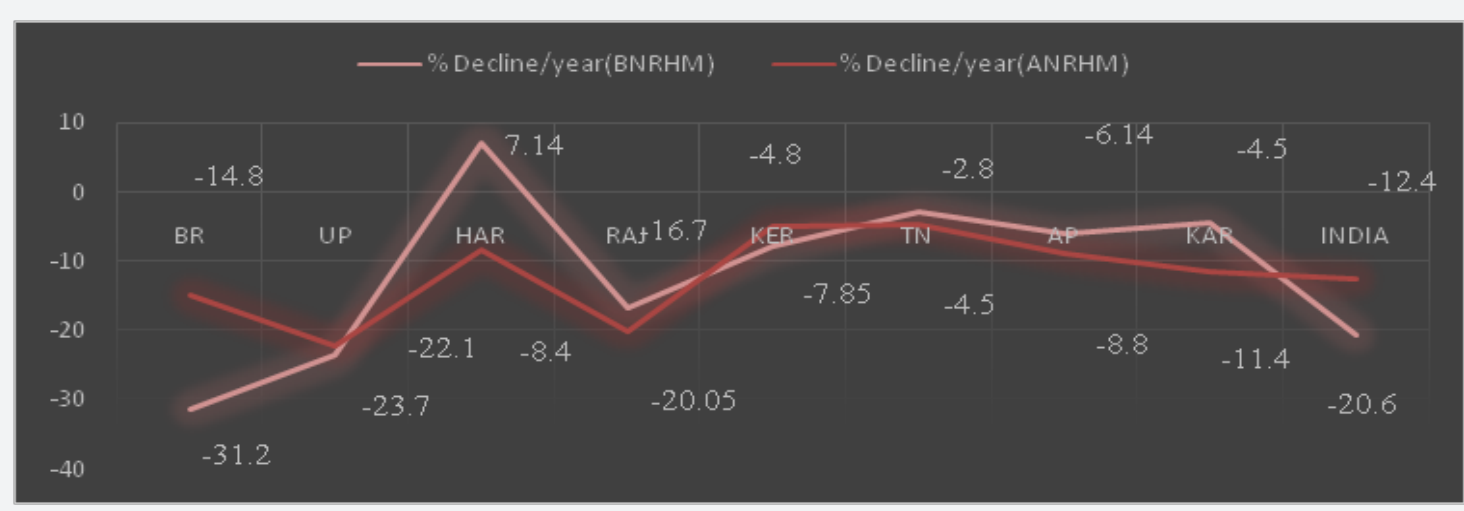

Chart 1: Percentage Change/year in MMR in Pre (1997-2004) and Post NRHM period (2005-2013).

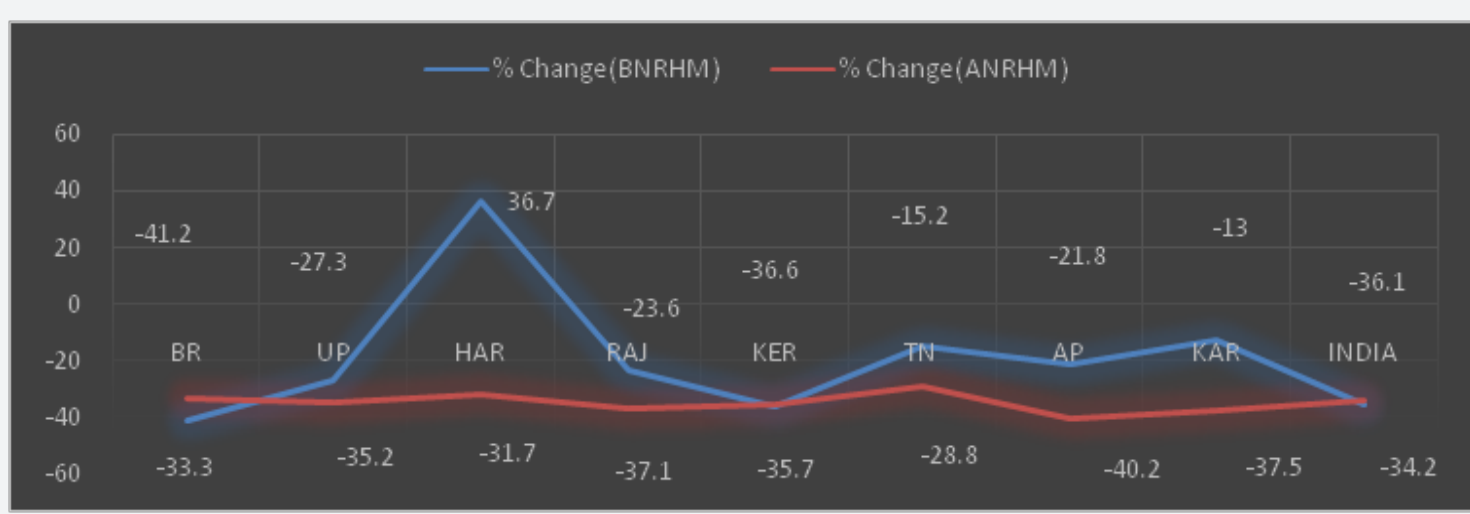

Chart 2: Percentage change in MMR In pre (1997-2004) and post NRHM (2005-2013) period.

The state wise scenario with respect to MMR is found to be varying in nature; states from the northern part of the country showing higher pace in MMR reduction in both pre and post NRHM period. The states like Bihar, Uttar Pradesh and Kerala has shown a higher pace in MMR reduction before NRHM, while the states like Andhra Pradesh, Karnataka, Tamil Nadu, Haryana and Rajasthan is showing higher decline in MMR in the post NRHM period. This improvement is expected to decrease the disparity ratio among states with respect to health status of women.
Chart $1 \& 2$ showing the disparity ratio of India and her states. In the pre NRHM period MMR reduction was higher in India as compared to post NRHM. The difference in pre and post MMR reduction rate was not significant meaning that NRHM does not accelerate the pace of MMR reduction successfully. National Rural Health Mission is a very progressive program as it helps in to the development of the country by a channel of improving health standard of the people. NRHM is in the starting phase of its implementation. In 2012 it has completed his 7 years. The 
argument here is that the factors such as Emergency Obstetrician Care (EmOC), availability of blood transfusion, public healthcare centre, paramedical staff, and caesarean facilities are short to cater to such a huge population (Ministry of Health and Family Welfare) and hence acceleration in MMR reduction may not be very high.

At the conclusion we can say that NRHM does not show any improvement in the health of women especially during their pregnancy. The expected result of NRHM in reducing health disparity and number of maternal deaths are not observed even after the completion of 7 years of implementation. There are a number a reasons behind the failure of NRHM with respect to women health in general and MMR in particular. From the implementation (2005) to the latest maternal mortality report (2011-2013) is a very short period of time and every big program needs a long time to accelerate the pace of its success. Thus, NRHM required longer time to boost the MMR reduction in India and her states. Under the NRHM some other schemes were also started at the later period of first phase. The schemes are like Janani Shuraksha Yojna (JSY), Mother and Child Health Tracking System, Maternal and Child Health wings etc. These schemes and services help a lot in improving maternal health. The other reason behind slow pace in MMR reductions in post NRHM period are the lack of proper implementation of such schemes and services under the NRHM hence these are occurred variedly across the Indian states. Although the number of institutional deliveries has increases since the launch of JSY [5]. Yet the prevention of maternal deaths has not increased proportionately because of bad behavior of Healthcare centre staff towards the newly mother, scolded during delivery, not being provided a bed even though it is available, shifting newly mother and her infant to the floor of the veranda to save the bed from getting dirty which causes a high risk of infection or even death of mother and child Khan et al. [5]. Number of women deliveries in medical facilities has been increasing apparently, healthcare institutions is the reason for the slow pace of reduction in MMR. The unavailability of healthcare centre, skilled healthcare professionals and poor quality care in healthcare institutions are some of the vivid reason for such a huge healthcare disparity and slow reduction in maternal mortality ratio [6-12]. Many developing countries have already achieved the far better MMR than India. Thus, we need to look, review and critically analyze the policies and programs of those countries where MMR is better than us.

\section{References}

1. Ayele DZ (2014) Factors affecting Utilization of Maternal Healthcare Services in Kombolcha District, Eastern Hararghe Zone, Oromia Regional State, Eastern Ethopia. International Scholarly Research Notices 2014(2014): Article ID 917058.

2. Special Bulletin on Maternal Mortality 2010-12. Sample Registration System, Office of the Registrar General of India, Government of India, India.

3. Special Bulletin on Maternal Mortality 2011-13. Sample Registration System, Office of the Registrar General of India, Government of India.

4. Hanimi Reddy, Pradhan MR, Ghosh R, Khan AG (2012) India's Progress towards millennium development goals 4 and 5 on infant and maternal mortality. WHO South East Asia J Public Health 1(3): 279-289.

5. Khan ME, Hazra A, Bhatnagar I (2010) Impact of JananiSurakshaYojna on selected family health behaviours in rural uttar Pradesh. The Journal of Family Welfare.

6. Dongre A, Kapur A (2013) How is Janani Suraksha Yojna Performing in Backward Districts of India? Economic and Political Weekly, 48(42).

7. National Health Mission, Ministry of Health and Family Welfare, Government of India.

8. National Rural Health Mission, Ministry of Health and Family Welfare, Govt. of India.

9. Pandey K (2015) Maternal Mortality: India Likely to miss MDG target.

10. Special Bulletin on Maternal Mortality 2004-2006. Sample Registration System, Office of the Registrar General of India, Government of India.

11. United Nation Development Programme (India), Millennium Development Goals.

12. http://www.mohfw.nic.in

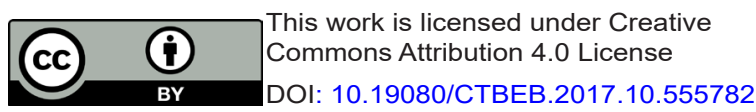

\begin{tabular}{l} 
Your next submission with Juniper Publishers \\
will reach you the below assets \\
- Quality Editorial service \\
- Swift Peer Review \\
- Reprints availability \\
- E-prints Service \\
- Manuscript Podcast for convenient understanding \\
- Global attainment for your research \\
- Manuscript accessibility in different formats \\
( Pdf, E-pub, Full Text, Audio) \\
- Unceasing customer service \\
Track the below URL for one-step submission \\
https://juniperpublishers.com/online-submission.php \\
\hline
\end{tabular}

